\title{
Special Focus Highlighting Diversity of Work in This Field
}

\author{
Ryan M. Deacon ${ }^{1}$
}

(C) Springer Science+Business Media New York and ASM International 2015

This issue of Metallography, Microstructure, and Analysis (MMA) features articles from the 2014 Microscopy and Microanalysis Annual Meeting, held August 3-7, 2014, in Hartford, CT. The authors were invited to submit expanded versions of their conference papers for full peer review and publication in MMA. As in the past, the guest editor for these papers was James Martinez of NASA Johnson Space Center, and I extend him the journal's gratitude for his time and efforts.

This year, to highlight the variety of work that is being explored in this field, authors from a diverse range of topics were invited to submit a manuscript. The materials discussed in these papers include nanoparticles, oxide coatings, and $\mathrm{Ni}-\mathrm{Ti}$ alloys. Together, these papers illustrate the power of modern microscopy and microanalysis tools, and how they are being applied to not only improve existing materials, but to facilitate the development of new materials as well.

The publication of papers from leading technical conferences promotes further dissemination of knowledge and expands the reach of the authors' work. I hope that the publication of these papers in $M M A$ will allow our readership to build upon the results presented therein and to develop new ideas and approaches for materials analysis.

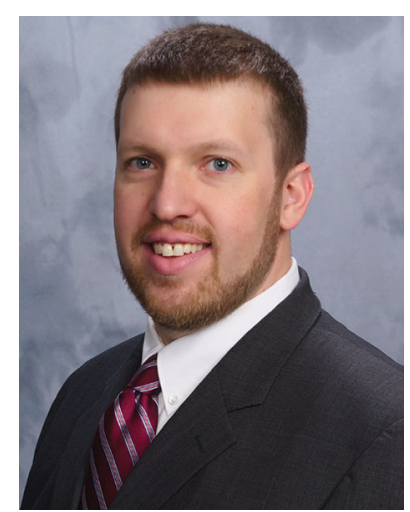

Ryan M. Deacon

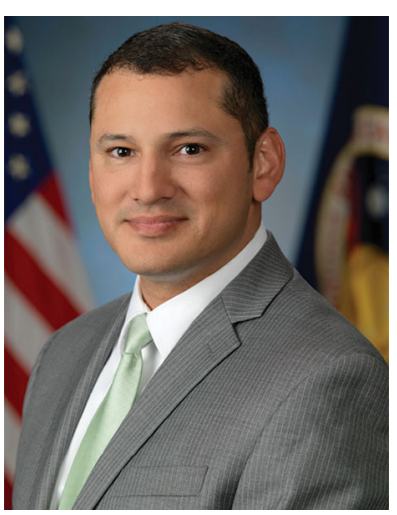

James E. Martinez

Ryan M. Deacon

ryan.deacon@asminternational.org

1 DuPont Engineering Research and Technology, DuPont Co., Experimental Station, E302/117D,

P.O. Box 80302, Wilmington, DE 19880-0302, USA 